\title{
“CONVERTIR A LA RELIGIÓN, QUE ES FIN Y SOLO PUEDE SER FIN, EN MEDIO": LA CRÍTICA A LA TEOLOGÍA DE LA LIBERACIÓN DESDE EVANGELII NUNTIANDI A PUEBLA EN LAS PÁgInAs de LA REVISTA TEOLógica de CELAM *
}

"Religion Conversion is an end and can only be an end, in means": Criticisms Directed Against the Theology of Liberation from Evangelii Nuntiandi to Puebla as published in Celam's Theological Journal

Marcos Jesús Fernández Labbé **

RESUMEN: El objetivo del presente artículo es reconstruir e interpretar históricamente un conjunto de críticas a la Teología de la Liberación, publicadas a lo largo de la década de 1970 en la revista teológica del Celam, Medellín. A partir de un enfoque de Historia Intelectual se interpreta al campo disciplinar de la teología como un espacio de controversias con implicancias políticas, disciplinares e institucionales, concluyéndose la reivindicación por parte de los autores analizados de una perspectiva teológica centrada en la Revelación, la autoridad magisterial y el rechazo a la secularización y politización que a su juicio implicaba la Teología de la Liberación.

PALABRAS CLAVES: Teología de la Liberación. Celam. Catolicismo. Historia Intelectual. Historia Política.

ABSTRACT: The paper analyzes the field of theology from the perspective of intellectual history: that is, as a domain of theoretical controversies having political, disciplinary, and institutional implications. It aims, from such an analytical perspective, to reconstruct and interpret a set of criticisms directed against the

* Este artículo es parte del proyecto Fondecyt 1170613 "Catolicismo y Política: Vocabulario Conceptual, Opinión Pública y Acción Política desde una perspectiva comparada, 1970-1985".

** Universidad Alberto Hurtado, Santiago, Chile. 
Theology of Liberation throughout the 1970s in Medellin, the journal of Celam's theological studies. Those criticisms, the paper concludes, reject secularization and politicization, which would be based on Liberation Theology, while claiming that the correct theological analysis is based on Revelation and the Magisterium.

KEYWORDS: Theology of Liberation. Celam. Catholicism. Intellectual History. Political History.

\section{Introducción}

$\mathrm{C}$ omo una gran cantidad de análisis han demostrado para América Latina, la participación de agentes políticos inspirados por el catolicismo ha sido, a todo lo largo del siglo XX, una constante antes que una excepción. Desde flancos opuestos y de honda divergencia doctrinal, posiciones como las de TFP, Cristianos por el Socialismo y las distintas denominaciones de las Democracias Cristianas supusieron una sistemática voluntad de estos agentes religiosamente inspirados de incidir activamente en la construcción de lo temporal y en la toma de partido en contextos de profunda conflictividad política (ANDES Y YOUNG, 2016; MALLIMACI, 2008; RODRIGUES, ZANOTTO Y COPPE CALDEIRA, 2015; STUVEN, 2014). Una parte de este espectro católico derivó hacia un acercamiento a la izquierda política y sus opciones políticas y conceptuales, incluidas en ellas el marxismo, tradicionalmente concebido como el antagonista radical del cristianismo, a nivel no solo político, sino que filosófico y doctrinal (ÁLVAREZ, 2009; CARRIER, 2014; FERNÁNDEZ, 2016; LÖWY, 1999).

En ese tránsito -recorrido en América Central, Brasil, Colombia, Perú, Chile y Argentina y de forma muy visible protagonizado por organizaciones de sacerdotes y religiosas como Golconda, ONIS, el Movimiento de Sacerdotes para el Tercer Mundo y Cristianos por el Socialismo (DONATELLO, 2010; DRI, 2015; FERNÁNDEZ, 2017; JO, 2005; MARTIN, 1992; PAGANELLI, 2016; PÉREZ, 2016; RAMÍREZ, 2006; RAMMINGER, 2019; RESTREPO, 1995) - la Teología de la Liberación jugó un papel esencial, en tanto dotó a corrientes muy diversas de un lugar de encuentro teológico-político en el concepto de la liberación, que reunía de forma doctrinal tanto una interpretación contingente de la Escritura -bajo la égida del profetismo y el relato bíblico del éxodo y la salvación prometida a los oprimidos- como un compromiso activo con la transformación de las estructuras sociales, la primacía de la historia como factor de interpretación teológica y la visibilización de la acción política abierta de los agentes religiosos, ya no solo los laicos y laicas, sino también las religiosas, religiosos y sacerdotes.

Si bien una caracterización de esa naturaleza de la Teología de la Liberación no da cuenta de su complejidad y de la multitud de argumentos estric- 
tamente teológicos y de exegesis bíblica que la constituyen, en el análisis que aquí se presenta es suficiente, en tanto que lo que se busca discutir es el impacto crítico que este tipo de formulaciones propias del cristianismo liberacionista tuvieron en corrientes teológicas opuestas en el continente, dando cuenta así del tipo de argumentos elaborados para poner en cuestión no solo los conceptos centrales de la Teología de la Liberación, sino que también de su cualidad de ejercicio teológico. De esa forma, lo que aquí se busca en ubicar, en primer lugar, este recorte de controversias en el marco de un debate disciplinar e intelectual específico, en el que con las armas de la teología se enfrentó a un tipo de formulación teológica particular. Es por ello, un análisis de ciertas prácticas intelectuales que se articulan en el espacio de la discusión científica y así se legitiman como parte de un saber sobre la teología que operó como código de acceso a la formulación de tales o cuales interpretaciones sobre la Escritura y las relaciones entre lo trascendente y lo contingente.

Por ello, es decir, por el nivel teológico-intelectual en el que los debates que a continuación se reseñan se ubica, es de particular relevancia destacar que las argumentaciones críticas recogidas fueron publicadas en la revista Medellín, albergada al interior del Celam (Consejo Episcopal Latinoamericano) desde 1975 y expresiva por ello de las opciones que la Jerarquía continental -siempre con matices y excepciones, por supuesto- suponía como más cercanas a la correcta interpretación teológica de la realidad. Esa opción, que sin duda tenía mucho de política, recurrió en este espacio al debate teológico, entendido quizás como el lenguaje exclusivo en el que las divisiones y controversias al interior del mundo católico institucional debían de ser expresadas y resueltas. En esa lógica, el rechazo al clericalismo -la intervención política de los agentes eclesiales-, al acercamiento al marxismo, a la exaltación de la historia como lugar de interpretación teológico; así como la reivindicación de la Palabra por sobre su contexto, la primacía del magisterio y la vocación escatológica del cristianismo, eran todas formulaciones de naturaleza disciplinar, pero con un calado político imposible de clausurar.

\section{Conceptualización de liberación: entre revelación y realidad}

El teólogo brasileño Boaventura Kloppenburg (1919-2009), con motivo de comentar el Sínodo de Obispos de 1974, redactaba una larga reflexión en Medellín en la que se preguntaba por "la relación que hay entre la índole escatológica de la salvación cristiana y el progreso humano temporal" (1975, p. 7), asociando a éste último con el concepto de liberación. Por ello, buscaba explorar la naturaleza de fidelidad o infidelidad a la labor cristiana de aquellas acciones de evangelización que no se comprometiesen directamente con el plano terrenal de la liberación. Es decir, “¿una 
acción liberadora (siempre en lo social, económico, político) pertenece a la misión propia de la Iglesia?" (p. 8). Las respuestas debían de estar, en primer lugar, en el breve apartado que el documento de conclusiones del Sínodo dedicaba al problema de la liberación, en el que se afirmaba "la conexión íntima que existe entre la obra de evangelización y la mencionada liberación", (p. 20), entendiendo que la "salvación integral del hombre" debía ser el motivo central de la acción eclesial, y esa acción debía "desde ahora realizarla", ( aquí pode deixar sem, pois são apenas expressões, não frases ) sacando "del mismo Evangelio razones más profundas y un impulso siempre renovado para promover la entrega generosa al servicio de todos los hombres, sobre todo de los más débiles y de los oprimidos, y para eliminar las consecuencias sociales del pecado, que se traducen en estructuras sociales y políticas injustas" (1975, p. 29). Del mismo modo, la Iglesia podría "evitar desviaciones en los mismos esfuerzos de liberación, de forma que ella misma no se quede dentro de los límites meramente políticos, sociales y económicos" (1975, p. 10).

Para el brasileño -que había participado en el Sínodo como "adiutor secretarii specialis"- las conclusiones en cuestión eran vagas, pálidas, poco aclaratorias y testimoniaban un afán de redacción apresurado y poco sólido. Por ello, asumía la responsabilidad de tratar el problema de la relación entre evangelización y liberación con el cúmulo de documentación y opiniones que habían alimentado al Sínodo, y no solo con su escueta misiva final. En esa genealogía, Kloppenburg advertía que la pregunta por dicha relación había sido explícitamente planteada como tema de debate al Sínodo por las Conferencias Episcopales de una decena de países, entre ellos Brasil, Chile, Cuba, Perú y Venezuela; y que el tono global de la aproximación sinodal había tenido que ver más con la cuota de urgencia y credibilidad que para la Iglesia el pronunciamiento a favor de la promoción humana significaba -a su juicio un acercamiento más bien político- que con una reflexión teológica.

En la senda de analizar desde esa perspectiva el problema de la liberación, el brasileño iniciaba su meditación a partir de "las desviaciones en los mismos esfuerzos de liberación" mencionadas por el documento sinodal, advirtiendo que había muchas "liberaciones" (1975, p. 10), en tanto todo humanismo se planteaba la desalienación del sujeto, y entre los humanismos los habían no cristianos, e incluso anti-cristianos. Más aún, a su juicio el mismo cristianismo no debía limitarse a un humanismo, dado que "el hombre no es su propio fin ni el único ni el principal artífice y demiurgo de su propia historia" (1975, p. 14). La deriva de este olvido -que de alguna forma favorecía lo inmanente antes que lo trascendente de la naturaleza eclesial- se encarnaba en el "temporalismo" y en la creencia en la dicotomía entre evangelización y liberación y, muchas veces, la prioridad de la segunda para hacer efectiva la primera. De esa forma, y citaba para ello al presidente de la Conferencia Episcopal del Brasil, 
Aloysio Lorscheider (1924-2007), al interior de la Iglesia se multiplicaban las divisiones y surgía lo que denominaba "el tercer hombre de la Iglesia", es decir, aquel religioso o sacerdote que "hace poco caso de la vida y de la acción de la Iglesia", en tanto "quiere realizar su misión mediante el 'compromiso con los pobres', 'con los oprimidos', al margen de la Iglesia institucional". (1975, p. 1) Su finalidad sería que mediante "la destrucción de las estructuras sociales podemos llegar a la 'reforma' de las estructuras eclesiásticas y al nacimiento de una 'Iglesia nueva'" (1975, p. 17). En otras palabras, la "politización de la fe", cuyo epítome habría sido -según manifestaba en el Sínodo el obispo chileno Francisco Valdés Subercaseaux (1908-1982) - Cristianos por el Socialismo, que reunían temporalismo, politicidad y una "ingenua simbiosis con el marxismo" que favorecía la articulación de un peligroso "mesianismo temporal", en el que "el análisis y la praxis revolucionarios se erigen en criterios de interpretación del mensaje cristiano de salvación" (1975, p. 19).

Denunciadas entonces las desviaciones, el segundo paso de Kloppenburg consistió en analizar con atención la "íntima conexión" que el texto sinodal evidenciaba entre evangelización y liberación, y que en la reunión obispal anterior -1971- había sido declarada de forma mucho más taxativa como "dimensión constitutiva" de la tarea de salvación. En ese ánimo, junto con reseñar las escasas voces que argumentaban a favor de una total separación y subordinación entre una y otra, daba espacio a aquellas visiones -al parecer mayoritarias- de quienes creían en la liberación como parte "esencial de la evangelización", frase expuesta por Germán Schmitz (1926-), obispo auxiliar de Lima. En la misma senda, se identificaba a la "promoción de los derechos humanos" (1975, p. 23) como "requerida por el Evangelio" y "central en su ministerio", en la palabra de los Cardenales Paulo Evaristo Arns y John Joseph Krol (1975, p. 23) A la hora de matizar, el brasileño recogía aquellas opiniones y debates que resaltaban la creencia en la autonomía de la salvación con respecto a la liberación -en términos de que la primera operaba incluso ahí donde la promoción humana, el fin de la opresión o de la pobreza se hubiese logrado-, así como la poca claridad en las "responsabilidades" de la Iglesia en la liberación, ya que en ésta debían quizás participar los laicos y laicas en tanto miembros de la sociedad civil, y no necesariamente la Iglesia como institución jerárquica y misterio.

El problema de fondo para Kloppenburg era de naturaleza conceptual, en tanto no existían definiciones precisas en torno a los conceptos ejes del debate, en particular Salvación y Liberación, lo que provocaba que "ya no hay lengua común en la Iglesia" (p. 1975, p. 25). Por ello Kloppenburg emprendía su camino propio de conceptualización, abundando en primer lugar en las referencias a la naturaleza trascendental, no secularmente agotada, de la salvación cristiana, referida al pecado, al alma, a lo divino. Sin embargo, era imprescindible anotar que en la actualidad y a partir del Concilio Vaticano II la historia era incorporada al plano de la salvación, 
entendiéndose éste como integral. En la práctica, ello suponía entender a la historia como un "lugar teológico", pero que no podía -siempre para el brasileño- poseer prioridad sobre la revelación, más bien al contrario, los "signos de los tiempos" debían ser leídos a la luz de la revelación, y no a la inversa, en tanto "los acontecimientos de la historia no constituyen una nueva revelación". De forma conclusiva en este aspecto, Kloppenburg citaba en extenso las apreciaciones sobre el particular del obispado francés, que indicaba que esta interpretación evangélica de los acontecimientos temporales suponía la estrecha relación entre evangelización y liberación, en tanto "los esfuerzos humanos por la liberación son así un lugar de acogida y de profundización de la Revelación", y ésta permitiría que dichas iniciativas fuesen evaluadas "proféticamente" en sus "ambigüedades", así como la visibilización de "alienaciones más secretas y profundas", del mismo modo que el cuestionamiento de "los medios utilizados para liberar al hombre" y el desenmascaramiento de "los nuevos rostros de la idolatría". Así, el autor proponía una definición de liberación que la entendía "como parte esencial, si bien no exclusiva, de la salvación cristiana y como tal objeto directo de la evangelización" (1975, p. 34), labor que "debe asegurar que el proceso de liberación del hombre no quede aprisionado en los horizontes inmanentes de una liberación meramente política, social y económica, sino que se abra a la radicalidad de la liberación profunda del pecado" (p. 34). ${ }^{1}$

De esa forma, se hacía evidente, el hecho de que en la medianía de la década de los 70 se volvía urgente para un sector del catolicismo continental la construcción de definiciones críticas con respecto a la Teología de la Liberación, en tanto representaba un espacio de polémica que en distintas escalas involucraba no solo posiciones políticas relacionadas con la proximidad o distancia con respecto al marxismo y las distintas experiencias de cambio social y represión estatal acontecidas en el continente; sino que con la concepción que de la Iglesia como tal y su papel en la historia tenía la teología que en América Latina se desarrollaba. Así, el debate no solo era político-institucional, sino que profundamente disciplinar, y por ello se desenvolvía a partir de controversias de interpretación que ponían el acento en distintas hermenéuticas y lugares desde los que se debía pensar la incidencia temporal del catolicismo. Esta incidencia, sin embargo, no aparecía como un axioma inmediato sino que -y particularmente para las voces críticas a la Teología de la Liberación que aquí se analizan- debía ser fruto de una autocomprensión interna, de un conjunto de convicciones radicadas más en la ortodoxia que en la ortopraxis, términos que de algún modo polarizaban sintéticamente el debate (ANTONCICH, 1976, p. 7-35).

\footnotetext{
${ }^{1}$ Gran parte de este tipo de argumentos, referidos a la ambigüedad del concepto liberación y su potencial inclinación hacia lo temporal e inmanente, estaban presentes poco después en la exhortación papal Evangelii Nuntiandi. El seguimiento de la conceptualización de evangelización en el periodo -de evidente relación con lo aquí discutido- puede encontrarse en Ramírez-Trillos y Plata-Quezada (2020). (KLOPPENBURG, 1975, p. 6-35).
} 
Muy poco tiempo más tarde, en la segunda parte de 1976, el sacerdote argentino Enrique Cambón (1942-) se preguntaba si la originalidad que la Teología de la Liberación no había entrado en una etapa de agotamiento, "inmovilismo e incerteza", en tanto "son pocos los grupos y personas que reflexionen con profundidad y creatividad" (1976, p. 301). Y ello se debía en alguna medida, a juicio del argentino, a que "entre los sacerdotes que luchaban por un cambio de mentalidad y se jugaban por aquellas posiciones que inspiran la Teología de la Liberación, no solo muchos han dejado el ministerio, sino -lo que es más llamativo- un buen número de ellos abandonaron, junto con el sacerdocio, también la lucha activa", aburguesándose al trasladándose a vivir a países "donde antes indicaban el origen el origen y la expresión máxima del imperialismo, la opresión y el sistema capitalista". De forma alternativa, otros se habrían "pasado a la guerrilla", o en el caso de la que consideraba la mayoría, habrían "dejado de lado toda inquietud o interés por el servicio activo de sus hermanos" (1975, p. 301). Fuera de esta situación afincada en la experiencia personal de cada sacerdote, para Cambón en la base del letargo de la Teología de la Liberación se hallaba lo que definía como "una experiencia demasiado pobre de la Palabra de Dios" (1976, p. 302) entendida como "una no correcta impostación de la relación entre la Palabra de Dios y la experiencia de vida" (1976, p. 303), que el argentino graficaba con la interpretación estrictamente sociológica e histórica que Hugo Assman (1933-2008) hacía en “Teología desde la praxis de la liberación" (1973). Más aun, la expresión de esta condición se verificaba en todas aquellas comunidades que observaban "como modelo del Reino de Dios el estilo de vida de los marxistas", así como la creencia de que el acercamiento al marxismo era más eficaz que el contenido del Evangelio. Para Cambón ello era un síntoma de "raquitismo en la vida de las comunidades que así se expresan". Como alternativa, el argentino proponía un "círculo hermenéutico" que se articulaba a partir de "no descalificar las Escrituras, sino, humildemente, aprender nuevamente de ellas", en tanto "son necesarios una reflexión y un compromiso que sean expresión de la Palabra de Dios vivida. Una Palabra que alimenta la vida, y una vida que hace descubrir nuevas comprensiones de la Palabra, para abrir aún nuevos horizontes al compromiso de vida".

De esa forma, la situación de base que volvía crítico el momento de la Teología de la Liberación -y de alguna forma la vitalidad del compromiso cristiano con el cambio social- era el hecho de que ésta había centrado su atención y su dinamismo en la relación entre experiencia histórica-social e interpretación evangélica. Y era esa la relación que debía invertirse, en términos de que fuese el Evangelio el que movilizase la experiencia de cada cristiano, esa "palabra de Dios vivida" que en caso de no existir -de no estar teológicamente incardinada en el corazón de la acción católica en el mundo- provocaba que los mismos católicos buscasen "en otras fuentes las ideas y la mística que el cristianismo parece no haber dado del todo" (1976, p. 306). El impacto de ello era claro para el argentino: "cunde el 
desaliento, el desconcierto, la desunidad", corriéndose el riesgo de "volver a formas de cristianismo 'religioso' y adormecedor" (1976, p. 306). Como corolario, "el pensamiento que debía alimentarse de esa praxis va poco a poco perdiendo originalidad, potencia y profundidad" (p. 306). El efecto de la inversión que Cambón proponía era la vía de revitalización no solo de una Teología de la Liberación, sino de la intervención católica en lo social: "si sembramos acción y revolución, sin bastante Palabra de Dios vivida debajo, nuestra acción no tiene raíz. Si en cambio sembramos Palabra de Dios, quienes se ponen a vivirla sacan, solos, las implicancias revolucionarias que posee, a nivel experiencial, estructural y de pensamiento" (p. 306) (CAMBÓN, 1976, p. 301-307). De esa forma, en la argumentación de Cambón se aliaba explícitamente por un lado lo teológico y su núcleo representado por la Palabra revelada; y por otro la intervención en lo temporal. El factor crítico era -si es posible expresarlo así- el predominio que lo político-sociológico ejercía en algunas interpretaciones de la Teología de la Liberación sobre el prisma estrictamente teológico que, en este caso para el argentino, debía necesariamente de primar.

\section{El lugar de la teología}

Boaventura Kloppenburg volvía -a fines de 1976- a someter a cuestionamientos al pensamiento y la acción motivadas por la Teología de la Liberación entre los cristianos, dando cuenta de forma sumaria las concepciones que dicha teología elaboraba en torno a las causas de la miseria latinoamericana y las vías de su liberación, ambas etapas marcadas a su juicio por concepciones de raíz marxista y asociadas a la lucha de clases. En lo que aquí más interesa, una definición de síntesis del brasileño apuntaba a que "la teología basada en esta liberación propone como punto de partida del quehacer teológico no un análisis o interpretación de la realidad, sino la transformación de la realidad: esa sería la verdadera praxis". Y por ello, para la Teología de la Liberación, era ésta "praxis liberadora el horizonte desde donde debe ser contemplado el Evangelio y el principio organizador de toda la teología" (1976, p. 522). Más aún, "el sujeto de creación teológica es el mismo sujeto de la praxis liberadora, es decir: únicamente el pobre o mejor el pueblo que tiene conciencia de ser oprimido y lucha por su liberación" (p. 522).

Esas definiciones motivaban en Kloppenburg más de medio centenar de aprehensiones formuladas como breves preguntas problematizadoras, entre las que es aquí relevante recordar un puñado:

Si una eventual violencia en la praxis revolucionaria es una actitud evangélica

Si la praxis u ortopraxis no es tomada como criterio y tribunal inapelable (con un concepto puramente pragmático de la verdad) y no solamente como criterio de la veracidad o credibilidad del mensaje evangélico; 
Si y en qué sentido la praxis revolucionaria es un 'lugar teológico', o hasta el lugar de hermenéutica y el punto de partida de una nueva teología...

Si el sujeto único de la teología es el pobre o el pueblo en cuanto comprometido con la lucha libertadora (KLOPPENBURG, 1976, p. 523).

Pues bien, si estas eran las condiciones de inicio de la reflexión teológica y política de la Teología de la Liberación, también debían ser de interés sus proposiciones en el "punto de llegada", es decir, en el programa que sus adeptos suponían para la sociedad y la Iglesia. El análisis de Kloppenburg expresaba una suerte de utopía liberadora, en la que tras la victoria de la revolución se sucedería

una situación de 'hombre nuevo', caracterizada por la igualdad social, la fraternidad, la corresponsabilidad, la participación activa en la vida política y cultural, etc. El 'pueblo' así liberado sería el único sujeto verdadero y auténtico de la 'nueva Iglesia', la Iglesia Popular, desde el pueblo y para el pueblo, la única capaz de desbloquear las conciencias, de desideologizar la Iglesia oficial, institucional e interclasista, de reapropiarse de la Escritura haciendo una más auténtica relectura (materialista) del Evangelio para redescubrir su sentido originario y reinterpretar la fe con la mediación de las Ciencias Sociales. Sería una Iglesia clasista, con nuevas formas de vivir la fe, de celebrar la Eucaristía, de reemplazar toda la sacramentalización, buscando una nueva espiritualidad y nuevas formas de oración. No se puede esperar que estas nuevas formas surjan del seno mismo de la Iglesia oficial: es el proceso revolucionario mismo el que hará posible una revolución dentro de la Iglesia. Esta debe aceptar ser continuamente cuestionada, pues de hecho aparece como un obstáculo para que muchos cristianos hagan la realidad de su compromiso liberador. (KLOPPENBURG, 1976, p. 523-524).

Así, lo que el brasileño hacía era poner en tensión -y hermanar hasta lo inconfundible- los presupuestos de futuro tanto del marxismo como de la interpretación de la Teología de la Liberación que Kloppenburg seccionaba, particularmente en los efectos que su implantación histórica tendría no solo sobre el cristianismo como tal o sus instituciones, sino sobre la misma Teología de la Liberación y los criterios de praxis que a su juicio la fundaban. De forma coherente, en sus conclusiones el profesor de teología en el Instituto Pastoral del Celam se preguntaba si, a fin de cuentas, la Teología de la Liberación era teología o ideología, y para rechazar la primera opción tomaba como ejemplo al "ideólogo de Cristianos por el Socialismo" Pablo Richard (1939-), en opinión del cual la reflexión cristiana no debía partir ni de la teología, ni de la fe, ni del Evangelio, y menos de la Iglesia; sino que de las condicionantes de la conciencia de clase. ${ }^{2}$ De tal modo, y siempre con el eje de conflicto instalado en la relación entre teología y marxismo, el ejercicio emprendido por el teólogo brasileño se

${ }^{2}$ Estas proposiciones las extraía Kloppenburg del texto publicado por Richard en 1975 en la Editorial Sígueme, Cristianismo, lucha ideológica y racionalidad socialista. 
posicionaba desde una perspectiva disciplinar, y era ésta la que permitía evaluar la corrección o distorsión de las proposiciones propias a la Teología de la Liberación. Kloppenburg no buscaba matices o vías de acuerdo. Lo que hacía era desfondar la pretensión teológica -disciplinar, intelectual- de la corriente que encabezaba Gustavo Gutiérrez (1928-).

En muy similar senda se encaminaba, ya en 1978, el sacerdote y teólogo alemán Karl Lehmann (1936-2018) al momento de emprender un trabajo de reflexión crítica en torno a la Teología de la Liberación que, dando cuenta de sus principales autores y algunos de sus impactos fuera del continente, se concebía como un ejercicio que debía realizarse al mismo tiempo que se daba cuenta del "grito múltiple de los pobres" y los oprimidos a los que esa teología buscaba dar voz, apartándose del plano de la mera teología "escrita". Dicho ello, sin embargo, el circuito de la crítica era orientado por la pregunta de "si ciertos proyectos teológicos acerca de la 'liberación' son el camino adecuado para dar expresión, de la mejor manera posible, a la aspiración por un mundo mejor y fraternal" $(1978$, p. 6). Es decir, la validez, pertinencia y eficacia de la incidencia teológica en lo temporal. De esa forma, y tras reconocer el carácter situado de su análisis en tanto europeo, Lehmann subrayaba el carácter fuertemente original de la Teología de la Liberación en el hecho de que "esta Teología se inicia en la concientización de la situación propia, planta sus raíces en la praxis histórica de la liberación y hace entrar en el compromiso concreto" (1978, p. 7). Este compromiso, a su vez, se verificaba en la tarea "del reconocimiento del ser hombre de los explotados" y "crear una sociedad justa, fraternal" (p. 8). Solo el cumplimiento efectivo de estos objetivos - profundamente terrenales- era lo que objetivaba al mismo cristianismo, en tanto "la exégesis de la palabra de Dios acontece en último término en los hechos", ya que "solo cuando la verdad se realiza y demuestra, la comprensión de la fe se libera entonces de toda forma de idealismo" (p. 8).

En aspectos más generales, Lehmann recogía a su vez el campo de crítica que representaba la definición que la Teología de la Liberación hacía de la comunidad entre historia de la salvación e historia profana, así como de la identidad entre Iglesia y Mundo, entre ámbito trascendental y contingencia, naturaleza y gracia, etc. Ello se traducía además en el rechazo a todo dualismo, particularmente "en el ámbito de lo político y la comprensión de la fe". Así, "la intención es clara: la historia de la salvación acontece en el contexto de la historia del mundo, la fe no se añade simplemente de manera extrínseca (como superadditum) a la historia" (1978, p. 10). Tal y como el carácter original de la Teología de la Liberación era esta articulación entre teología y compromiso, esta vinculación entre salvación y mundo suponía a su vez que era la "praxis de la liberación" el "locus theologicus" primordial, encarnado en el compromiso con los más pobres, compromiso cristiano que "no es neutro políticamente ni éticamente inocente". De esa forma, Lehmann reseñaba la labor que este lugar teológico adscribía 
a los suyos: "debe el teólogo, cuando se pone al servicio del Pueblo de Dios, convertirse en el intérprete reflexivo, crítico, de la praxis vital de los pobres, de los marginados, de la clase explotada. Su voz no puede hacerse audible más que por el movimiento histórico de liberación" (1978, p. 11). Este punto, nuevamente, a juicio de Lehmann debía ser revisado en tanto, si bien la historia en su conjunto, la historia de la misma Iglesia y la operatividad del Espíritu Santo en la historia eran lugares teológicos válidos y reconocidos, ello no suponía que fuesen -y en el caso puntual de la historia como liberación planteada por la Teología de la Liberación"en sí mismos teológicamente normativos", sino que "significan un reto elemental y es así esencialmente, en su carácter permanente como provocación y llamamiento a la identificación, más allá de un simple 'punto de partida' o un 'horizonte' para el anuncio del mensaje cristiano" (1978, p. 12). Sin embargo, esa cualidad imprescindible de la historia como "lugar de comprobación y ámbito de lucha entre los poderes buenos y malos" no tenía "por sí validez incondicional". Así, a juicio del alemán, "para el cristiano, la luz de la palabra de Dios, tal como ella es anunciada en la Iglesia y por el servicio del Magisterio eclesiástico, es la realidad primera, con la cual debe ser examinado todo hecho, si quiere ser una fuente de conocimiento teológico" (p. 12). De esa forma,

la situación del pobre y del sometido es sin duda algo así como un ámbito completamente elemental de comprobación del cristianismo latinoamericano, ella es también al mismo tiempo la línea de ataque para el kerygma, pero, en cuanto tal, ella no puede ser de manera inmediata una norma y exigir así dignidad teológica en el sentido de un 'locus theologicus' propiamente dicho. El mundo histórico es incuestionablemente el lugar del evangelio, pero éste no se desprende de él ni agota tampoco su dinamismo en él (LEHMANN, 1978, p. 12). ${ }^{3}$

El efecto del tipo de definiciones que Lehmann buscaba matizar o poner en cuestión en la Teología de la Liberación latinoamericana se verificaba en la creencia de ésta del vínculo íntimo entre fe y praxis, entendiéndose a esta última como esencialmente política, y por ello, "cargada conflictualmente por necesidad", dado que para la Teología de la Liberación "la sociedad justa es solo posible pasando por el camino de la confrontación entre grupos humanos con intereses y puntos de vista enfrentados" (1978, p. 14), derivándose el hecho de que "lo político alcanza una nueva dignidad teológica". Para dar cuenta de la crítica a este tipo de definición -que se encarnaba en movimientos como los Cristianos por el Socialismo y en la introducción de la lucha de clases como una posición legitimada por éstos- el alemán sintetizaba un conjunto de debates dados en torno a las europeas teologías de la esperanza, de la revolución y política, que le permitían sostener que "el mensaje bíblico no puede disolverse de manera

${ }^{3}$ Sobre el problema de la historia como lugar teológico, Costadoat, (2015, p. 179-202) y Schickendantz, (2014, p. 157-183). 
autosuficiente en la consideración del ser del presente y realizado, sino que se extiende más allá hacia la entrega, hacia la misión y así hacia el futuro de su promesa" (p. 15), es decir, poniendo el acento en lo porvenir trascendente antes que en la concreción política-secular incardinada en las formulaciones de la Teología de la Liberación. En esa misma lógica, la experiencia de la "praxis de la fe cristiana" no podía ser separada de "el acontecimiento salvífico definitivo en Jesucristo", marcado por un "todavía no" de su ocurrencia, aquello que "todavía no ha llegado a realizarse, ni a adquirir validez y por lo tanto permanece por fuera en el mundo histórico" (p. 15).

Como se puede reconocer, el problema central de estas oposiciones tenía que ver con el papel de acendrada normatividad que la Teología de la Liberación le asignaba a la praxis cristiana, en su acepción, política y liberadora, y por ello, como locus theologicus. Para poner en cuestión esta centralidad de la praxis así entendida, Lehmann abordaba la tensión entre la teología como una teoría y la acción cristiana como praxis, distinguiendo los planos de intervención y los alcances de cada una, así como sus mutuas conexiones y autonomías. Fuera de ello, sin embargo, en lo central el alemán sostenía por un lado que "el llamado a la sola acción puede fácilmente convertirse en carta libre para el capricho y para la dominación" (1978, p. 16); y que "la teología como teoría ayuda a evitar que el evangelio de Jesucristo - precisamente en condiciones sociales urgentísimas- sea recortado en una acción orientada de manera solamente instrumental o funcional", recordando por ello "la soberanía e indeductibilidad del mensaje cristiano" ( 1978, p. 16). Una vez más, se ponía entonces en la dimensión trascendente del cristianismo la baza central de la crítica a la Teología de la Liberación, aun cuando esta crítica era elaborada por la disciplina dedicada a su análisis más racional, en tanto a la misma teología se la subordinaba al papel de la teoría, y por ello "solo obligada con la verdad", la que no residiría ni en la historia, ni en la praxis, y mucho menos en el "primado de lo político", en tanto "con la muerte de Jesucristo y con las perspectivas que se siguen de ella, lo político ya no es para el hombre la instancia determinante y capaz de dar sentido" ( 1978, p. 16).

Más aún, en la insistencia en la centralidad de lo político radicaba el riesgo de "tendencias totalitarias" (1978, p. 17), como parecía advertirse en la legitimación por parte de segmentos de la Teología de la Liberación de "la violencia revolucionaria o la lucha de clases como único medio para el cambio de la sociedad" (1978, p. 18), consecuencia en opinión de Lehmann de la identificación entre "'praxis de la fe' y la 'fe como praxis". Así, la proposición de que la vía de la praxis verdaderamente cristiana era la lucha contra la opresión, y ésta era así el verificador de su validez, dejaba "sin considerar que la Iglesia y el cristiano dan testimonio de una pluralidad de formas prácticas de comportamiento en medio de la miseria social" (1978, p. 18), como demostraban a su juicio las iniciativas de 
"acción no violenta". Del mismo modo, esta primacía de la política en clave revolucionaria permitía a Lehmann volver sobre el tópico crítico de la oposición entre lucha de clases y universalidad del amor cristiano, en términos de que "desde el evangelio no se puede, ante el compromiso con toda decisión en favor de determinados grupos borrar el dato fundamental del mensaje cristiano, a saber, que la Iglesia debe comunicar sin ninguna limitación el amor a Dios a todos los hombres" (1978, p. 24). En ese sentido, para el alemán, "el partidismo exclusivista es claramente marxista", y de forma más general, la suposición de que la única vía legítima de la fe era la revolución socialista suponía la necesidad de enfrentarse al axioma de que las opciones políticas "deben ser decididas con los medios y el realismo de la ética política", y no así de la ética cristiana o la inspiración trascendente o profética. De esa forma, la misma Teología de la Liberación no podía "escapar de la objeción de condicionamiento ideológico" (LEHMANN, 1978, p. 3-26). Así, el trabajo del teólogo alemán se concentraba tanto en una crítica de índole teológica, disciplinar, hermenéutica; y por otro, un cuestionamiento -en gran medida informado por las definiciones teológicas- de las opciones políticas de la Teología de la Liberación, o si se prefiere, del vínculo necesario que establecía entre el cristianismo y un tipo específico - político- de praxis de la fe cristiana.

Un año más tarde, el jesuita italiano afincado largas temporadas en el Perú Francisco Interdonato (1924-1991) -en ese momento profesor de Teología Sistemática de la Facultad de Teología de Lima- concentraba su crítica a la Teología de la Liberación en una clave muy similar, en términos del rechazo hacia la priorización de la política como un campo legítimo así de acción como de verdad para el ejercicio teológico y sacerdotal, en tanto el "objeto primario" del Magisterio "son las verdades de Fe doctrinal o de Fe práctica (moral) reveladas", disponibles en la "Revelación sobrenatural (Escritura y Tradición)". Ante ellas, cualquier verdad que asumiera entre sus premisas un factor extraño a la revelación -"una disciplina o ciencia natural y humana" (1979, p. 305) - pertenecía al objeto secundario de atención magisterial. Esa definición a primera vista formal, derivaba en la argumentación de Interdonato en una reflexión en torno a la licitud y pertinencia de la intervención política de la Iglesia Católica, que como regla general debía "mantenerse en el orden de los principios" y no en la certificación o condena de alguna fórmula en específico, en tanto solo en el plano de los principios podía verificarse "la asistencia del Espíritu Santo". En la base de ello se encontraba la creencia de que el nivel de la aplicación histórica-política era un campo de la autonomía del ser humano, ya que de no ser así la divinidad habría establecido por sí misma un orden político-económico determinado. En esa perspectiva, entonces, la preocupación por el orden político era estrictamente humana, pero ajena para aquellos que se habían consagrado al universo de lo revelado y a la Iglesia como institución, que se ubicaba de esa forma en una suerte de neutralidad gracias a su abstinencia de figuración política. Esa era la 
fuente de error de la Teología de la Liberación, que ponía como eje de su reflexión y su acción -“absolutizaba” en palabras del jesuita- en la política.

Si bien la actualidad de este fenómeno se inscribía en las corrientes post-conciliares y la situación del Tercer Mundo, para Interdonato el centrase en ese tipo de factores no era sino expresión de un "miope provincialismo", en tanto la larga duración del problema se remitía al constantinismo, es decir, al objetivo de "deslizar a la Religión hacia la política", convirtiendo así "la herejía en una cuestión política" o "disfrazando una opción política en religiosa". Justamente esa última opción era la que percibía "como tan abrumadora y peligrosa en nuestros días" debido a "su sacralización obrada por una corriente teológica" que vinculaba a Gustavo Gutiérrez y que definía como un "neo-constantinismo de izquierda" que "tiende a convertir a la Religión, que es fin y solo puede ser fin, en medio, aunque sea para el más noble de los fines humanos, la justicia y la liberación económica y política" ( 1979, p. 312). La orientación de todo lo anterior encontraba su origen -siempre de acuerdo a Interdonato- en la obra del teólogo bautista norteamericano -autor de The Secular City en 1966Harvey Cox (1929-), en tanto éste era la influencia clave en los "clérigos politizantes" de la Teología de la Liberación, que llevaban la consigna de "todo es política" ( 1979, p. 312) hacia el doble error de, primero, forzar la lectura político-contingente del Evangelio; y segundo, de "minimizar el riesgo de apoyar a partidos que absolutizan al Estado" por parte de agentes religiosos, evidenciándose en ello a juicio del jesuita un "germen de totalitarismo" ( 1979, p. 313).

Esa genealogía de la politización sacerdotal -que debía a su vez remontarse para Interdonato no al contexto histórico específico de América Latina sino que a la influencia de "los teólogos de la secularización y de la Teología Política del Primer Mundo"- se volvía más comprensible por lo que el autor denominaba "un fenómeno primordialmente clerical" que no sería otro que "la no asimilación - de lo cual todos, obispos, sacerdotes, religiosos, somos culpables- de la crisis de identidad arrastrada por los cambios intra y extra eclesiales de los últimos años" ( 1979, p. 316). El efecto de ello era por un lado la búsqueda en el ámbito de la política de una suerte de nuevo ethos cristiano, inspirado en la figura de los profetas del Antiguo Testamento -que en términos de Interdonato no anunciaban algún "programa humano ni la acción de los pobres y explotados, sino una intervención escatológica de Yahveh" ( 1979, p. 318)-; y por otro la ya mencionada re-lectura del Evangelio, "convertido en un mensaje político-social". A fin de cuentas, esta redefinición de identidad y de contenido de la intervención sacerdotal producía un empobrecimiento de ésta y el resultado indeseado de apartar al pueblo del catolicismo, esas mayorías que esperaban del clérigo "predicación y ministerio" (1979, p. 319) y de la Iglesia "Evangelio, auxilio en la Gracia para hacer frente a las dificultades de su vida de todo tipo, incluidas las socio-económico-políticas" (1979, p. 
319). Pero ese pueblo "no espera que se trate directamente de éstas, ni cree que sepamos hacerlo". Y al ver desconfiguradas sus expectativas religiosas "se pasan a sectas pietistas o, y esto es lo peor, se entregan a prácticas y creencias esotéricas y a temores de poderes precisamente de los cuales los libró el Cristianismo" (1979, p. 319). Por todo ello, ya al concluir, el teólogo advertía a sus pares:

solo si la religión se mantiene como instancia arraigada en el Dios de todos los tiempos, precisamente por ser atemporal, y de todos los hombres, por no ser partidista, podrá dar alma a las transformaciones y liberar a los que luchan por la liberación, a fin de que ellos mismos no se conviertan en represivos y opresores. No cabe dudar que estos efectos políticos los logrará entregándose a su misión religiosa; de ninguna manera diluyéndose en la política. ( INTERDONATO, 1979, p. 322).

Se reivindicaba así, de forma explícitamente crítica con respecto a lo predicado desde la Teología de la Liberación, una comprensión "tradicional" de la Iglesia y su magisterio, al que se proponía retornar al consuelo espiritual y la predicación, verdaderas antípodas de la vocación de incidencia temporal activa y análisis socio-político contingente que los teólogos de la liberación promovían. Así, el conjunto de la disputa político-intelectual y disciplinar revisado se reflejaba en el orden de lo doctrinal y lo institucional, remarcando con ello el desafío de alcance estructural que al interior del catolicismo latinoamericano representaba la Teología de la Liberación.

\section{Puebla y la Teología de la Liberación}

Una suerte de cierre -al menos cronológico- posible de proponer en el proceso de argumentación crítica referida a la Teología de la Liberación en el campo latinoamericano bien puede hallarse en el artículo del Obispo Auxiliar de la Arquidiócesis de México, Javier Lozano Barragán (1933-), publicado en la segunda mitad de 1979 y dedicado a sistematizar los planteamientos que la III Conferencia General del Episcopado Latinoamericano -realizada ese año en Puebla- había emitido sobre el tema específico de la Teología de la Liberación. Claramente, había sido uno de los temas más recurridos y que manifestaba con mayor claridad las diferencias existentes entre las distintas Conferencias nacionales, así como las orientaciones que el recientemente asumido Juan Pablo II (1920-2005) trasmitía al respecto al conjunto de la institución. La profundidad de estas controversias quedaban indicadas al menos en dos factores que Lozano consignaba: el hecho de que "en nombre de la Teología de la Liberación" se habría intentado "obstaculizar la preparación como la misma celebración de Puebla"; y que, al momento de la redacción de los Documentos finales, se sometió a votación la siguiente expresión: “Nos alegra también que la evangelización se venga beneficiando de los aspectos constitutivos de una reflexión teológica sobre 
la liberación, tal como surgió en Medellín" (LOZANO BARRANGA, 1979, p. 364). En la Comisión correspondiente la frase fue aprobada por 6 votos a favor y 5 en contra, y al ser presentado el Documento a la Asamblea, la misma frase recibió 52 requerimientos de que fuera retirada, arguyéndose que "se trataba de un texto que se prestaba a interpretaciones ambiguas, que era parcial y que era un respaldo a la Teología de la Liberación en su conjunto" (1979, p. 364). Por tal razón, la Asamblea se pronunció y de sus 176 miembros con capacidad de voto, 124 lo hicieron en contra y solo 52 a favor. A juicio del obispo, la principal línea divisoria en esta disputa estaba marcada por la adopción del marxismo como enfoque de análisis político y social, o si se prefiere, por la circunscripción del concepto de liberación a la lógica materialista e histórica que muchos autores de la Teología de la Liberación a su juicio sostenían, lateralizando la visión integral y trascendente que liberación debía contener desde un prisma católico. Por todo ello, el artículo en cuestión se dividía en la síntesis de los argumentos contrarios a la Teología de la Liberación que se habían elaborado en Puebla; y en las proposiciones positivas que permitían para la mayoría del Celam construir un efectivo y católico mensaje de liberación, o en palabras de Lozano, "una serie de elementos que se presten en el futuro para hacer una Teología de la liberación más amplia y acuciosa" (1979, p. 358).

La reflexión del mexicano se articulaba a partir de cinco insumos principales: la doctrina planteada en Medellín, el texto pontificio Evangelii Nuntiandi de 1975, el Discurso Inaugural de Juan Pablo II en la misma Puebla, el Documento de Trabajo elaborado por los Episcopados sobre el particular y el Documento final emanado de la Conferencia. El análisis se centrará aquí en estos dos últimos insumos. El Documento de Trabajo, elaborado a partir de los aportes de cada una de las Conferencias nacionales, constataba que para 17 de las 22 presentes la Teología de la Liberación representó un tema a discutir, particularmente las de México y Ecuador. En su contenido, reseñado por Lozano, debían destacarse por un lado los elementos considerados como positivos y aquellos criticables. Sobre los primeros, el vínculo evangelizador con los más necesitados y el compromiso sacerdotal con aspectos ya no solo espirituales o psicológicos de sus comunidades, atendiendo con ello "al aspecto temporal e histórico de la salvación". Entre los elementos sometidos a crítica el listado era más amplio y por su poder de síntesis, es importante citar al mexicano en extenso:

Algunas corrientes de la Teología de la Liberación contienen elementos que no pueden ser aceptados por un cristiano: la lucha de clases, la violencia, identificación del pensamiento cristiano con ideologías que prometen paraísos aquí en la tierra. La asunción del análisis marxista. El marcado acento inmanentista y horizontalista. La conciencia de los hombres como no determinante de su existencia social. La existencia social determinando la conciencia. Que la evangelización sea hacer tomar conciencia a los oprimidos de su situación y denunciar el estado de pecado de sus opresores para liberar a ambos mediante la lucha de clases. La aceptación de la crítica marxista de la religión 
como ideología favorable a los opresores y la pretensión de promover un cristianismo "no religioso" al que solo le quedaría la dimensión política por medio de la denuncia de las injusticias y la concientización del pueblo para la lucha revolucionaria. La afirmación de una fe proletaria y una fe burguesa necesariamente en pugna. El que la Iglesia no pueda ser verdadera comunidad de amor y reconciliación. El que la fe tenga que vivirse y pensarse solo dentro del universo de la experiencia revolucionaria y dentro de la realidad conflictiva y dialéctica de la historia. El desconocimiento de la Providencia, sobre todo a nivel social y estructural. El silenciar la intervención de Dios en la historia, o su equiparamiento con el puro poder inmanente de los procesos humanos determinados por la esfera económica. La reducción de la eficacia de la obra redentora del Cristo de la fe a una mera imitación o ejemplo del Jesús histórico. El tomar a Cristo como mero símbolo del pobre y del revolucionario y entender su redención reducida al ámbito político, económico y social. La contraposición excluyente de la Iglesia como red de comunidades, a la Iglesia, gran institución. El desconocimiento del Magisterio Jerárquico de la Iglesia como intérprete auténtico de la Palabra de Dios. La "Relectura" de la Palabra de Dios interpretándola por el acontecimiento liberador que consiste en el compromiso para la lucha de clases como verdadera praxis liberadora. El tomar la doctrina social de la Iglesia como un "Tercerismo", fruto de una lectura capitalista de la Escritura. El juicio de la religiosidad popular como algo alienante. La noción de "Iglesia popular" como algo exclusivo de los pobres socioeconómicos que se han concientizado para la lucha. El desconocimiento del valor eficaz de los sacramentos y su reducción a meros símbolos. (LOZANO, 1979, p. 362-363).

Dicho todo lo anterior, Lozano emprendía el análisis y comentario del Documento final de la Conferencia de Puebla, deteniéndose detalladamente en todos aquellos aspectos que identificaba como pertinentes a la Teología de la Liberación y su valoración episcopal. Como se habrá advertido, el ánimo de este comentario era más bien crítico, y se ponía como objetivo el colaborar con la elaboración de un auténtico acercamiento católico a la liberación, entendiendo al problema como un aspecto teológico que debía de corregirse. Por ello partía de la base del reconocimiento de los aspectos positivos de una reflexión teológica sobre el tema, tal y como el Documento de Trabajo lo había señalado. El recurso para ello era referirse constantemente a las teologías de la liberación, operando así el plural como una forma de distinguir matices. En lo básico, sin embargo, el parteaguas definitivo era la aceptación del marxismo, en tanto ello suponía "la total politización de la existencia cristiana; la disolución del lenguaje de la fe en el de las ciencias sociales y el vaciamiento de la dimensión trascendental de la salvación cristiana". (1979, p. 368)

En términos propositivos, Lozano esbozaba en la parte nuclear de su artículo una "Teología de la Liberación fundada en Puebla", que proponía que la inspiración basal de toda teología debía ser la Palabra de Dios, ejecutada muchas veces en los acontecimientos, los que podían ser correctamente interpretados en su capacidad kerigmática a partir de "un criterio hermenéutico. Este criterio es Cristo liberador que vive en el pueblo de Dios y 
se profesa en el sentido de dicho pueblo". A ello se sumaba la "Sagrada Escritura leída en la Iglesia y cuyo criterio hermenéutico de autenticidad es el Magisterio", (1979, p. 376) portador gracias al influjo del Espíritu del "carisma del discernimiento, en virtud del cual puede identificar la Palabra de Dios presente en el acontecer histórico; y su declaración hacer que la fe que se proclama sea la fe de toda la Iglesia". El resultado de esta red de efectos de autoridad sobre la interpretación de la realidad -fijadas de forma central en la Escritura- no era otro que el hecho de que "la ortopraxis de la Iglesia, Cristo hoy, que es a su vez la verdadera ortodoxia, se conoce por la fuerza de la misma ortodoxia" (1979, p. 376). Es decir, nuevamente se cuestionaba una de las conceptualizaciones axiales de la Teología de la Liberación, el recurso a la interpretación de la historia y la contingencia liberadora como clave de lectura del Evangelio, la denominada ortopraxis, devolviendo de algún modo el control de la teología y de la vida institucional al Magisterio.

\section{Conclusiones}

Así, y como conclusión de lo que hasta aquí se ha buscado señalar, el conjunto de divergencias desenvueltas a lo largo de la década de 1970 en torno a la Teología de la Liberación por parte de algunos de sus analistas más críticos se fundaron en un amplio espectro de flancos doctrinales, disciplinares, políticos e institucionales, que buscaban tanto reforzar el antagonismo entre catolicismo y marxismo, como la primacía que la palabra revelada en la Escritura debía de mantener por sobre el mundo contingente en la interpretación teológica, y por ello, en el actuar temporal de la Iglesia Católica y sus agentes consagrados. De forma nítida, los debates específicamente teológicos que se han analizado dan cuenta de un campo de controversias que -bajo las figuras del locus teológico y las relaciones entre ortodoxia y ortopraxis- daban cuenta de tradiciones intelectuales y políticas variadas en el seno del catolicismo institucional. Dicho ello, sin embargo, el hecho de que el lugar de enunciación de los debates aquí anotados fuese la revista teológica del Celam, y que el Documento final de Puebla los haya en alguna medida secundado, es expresivo de la posición de hegemonía institucional que, a lo largo del periodo revisado, ocuparon las voces críticas a la Teología de la Liberación en el nivel jerárquico del catolicismo latinoamericano.

Más allá de ello, los contenidos y modos de formulación de las controversias que se han reseñado permiten dar cuenta de una oposición cerrada, por parte de los teólogos citados, a cualquier posibilidad de aproximación entre cristianismo y marxismo, y más aún, del reemplazo o subordinación de la interpretación de la Escritura desde la misma Revelación al plano de lo histórico contingente. Este rechazo puede ser comprendido como 
una toma de distancia de cualquier intento de secularizar el cristianismo, es decir, de utilizar claves de análisis y estrategias de actuación histórica seculares -epitomizadas por el marxismo y la acción política en él inspirada- para llevar a cabo los objetivos que contingentemente se asociaban a los agentes católicos. ${ }^{4} \mathrm{Si}$ el marxismo -y quizás el conjunto del cristianismo liberacionista así como en específico la Teología de la Liberación- podía ser comprendido como una vía de secularización para un accionar más eficaz del cristianismo en América Latina, la posición teológica de la Celam se empeñó en clausurar esa vía y demandar un retorno a la interpretación magisterial, a la primacía de la trascendencia y al rechazo de la intervención política activa de las mujeres y hombres consagrados.

\section{Referencias}

ÁLVAREZ, D. Cristianismo y marxismo: ¿un diálogo de otro tiempo?. HAOL, 18, p. 161-177, 2009.

ANDES, S.; YOUNG, J. (Ed.). Local Church, Global Church. Catholic Activism in Latin America from Rerum Novarum to Vatican II. Washington, D.C: The Catholic University of America Press, 2016.

ANTONCICH, R. El Tema de la Liberación en Medellín y el Sínodo de 1974. Medellín, Bogotá, v. 2, n. 1, p. 7-35, 1976.

ASSMAN, H. Teología desde la praxis de la liberación. Salamanca: Sígueme, 1973.

CAMBÓN, E. Crisis de la Teología de la Liberación y Experiencia de la Palabra de Dios. Medellín, Bogotá, v. 2, n. 7, p. 301-307, 1976.

CARRIER, Y. Teología Práctica de Liberación en el Chile de Salvador Allende. Santiago: Ceibo, 2014.

CASANOVA, J. Public Religions in the Modern World. Chicago: University of Chicago Press, 1994.

COSTADOAT, J. La historia como "lugar teológico" en la teología latinoamericana de la liberación. Perspectiva Teologica, Belo Horizonte, v. 47, n. 132, p. 179-202, 2015.

\footnotetext{
${ }^{4}$ Esta noción de secularización que se propone dice relación no con su comprensión como la exclusión de las opiniones religiosas del ámbito de lo público -a la usanza de los planteamientos primeros de J. Habermas-, sino que con la evidencia de que en todo el mundo, y particularmente en América Latina, lo religioso convive en el ámbito público de forma legítima y muchas veces de forma políticamente articulada, siendo por ello los agentes religiosos protagonistas activos de la vida social, aun cuando no planteen como objetivo primordial el establecimiento de liderazgos religiosos, pero sí éticamente inspirados en sus creencias. Al respecto son muy relevantes los planteamientos en la larga discusión en torno al alcance del concepto secularización, algunos de cuyos hitos están representados por Casanova (1994); Gamper (2014); Habermas (2006); Mendieta y Van Antwerpen (2011); Monod (2012) y Taylor (2009).
} 
DONATELLO, L. Catolicismo y Montoneros. Religión, política y desencanto. Buenos Aires: Manantial, 2010.

DRI, R. La Iglesia que nace del Pueblo: de la Iglesia Oligárquica a la Iglesia Popular. Buenos Aires: Biblos, 2015.

FERNÁNDEZ, M. Los hijos de las tinieblas son más sagaces que los hijos de la luz. Pensamiento político católico y marxismo en Chile, 1960-1964. Izquierdas, v. 28, p. 27-65, 2016.

FERNÁNDEZ, M. Un reino de este mundo: la controversia en torno a Cristianos por el Socialismo. Chile, 1970-1973. In SANCHEZ, M. (Ed.) Historia de la Iglesia en Chile. Santiago: Universitaria, 2017. T. V.

GAMPER, D. La fe en la ciudad secular: laicidad y democracia. Madrid: Trotta, 2014.

GUTIERREZ, G. Teología de la Liberación: perspectivas. Lima: CEP, 1988.

HABERMAS, J. Entre naturalismo y religión. Barcelona: Paidós, 2006.

INTERDONATO, F. Fuente y Límite de la Autonomía de la Religión y la Política. Medellín, Bogotá, v. 5 n. 19, p. 305-322, 1979.

JO, Y-H. Sacerdotes y transformación social en Perú (1968-1975). Ciudad de México: UNAM, 2005.

KLOPPENBURG, B. Evangelización y Liberación según el Sínodo de 1974. Medellín, Bogotá, v. 1, p. 6-35, 1975.

KLOPPENBURG, B. Cuestiones Pendientes en la Praxis Liberadora. Medellín, Bogotá, v. 2, n. 8, p. 521-526, 1976.

LEHMANN, K. Problemas Metodológico-Hermenéuticos de la 'Teología de la Liberación'. Medellín, Bogotá, v. 4, n. 13, p. 3-26, 1978.

LÖWY, M. Guerra de Dioses. Religión y política en América Latina. México: Siglo XXI, 1999.

LOZANO BARRAGÁN, J. Elementos para una Teología de la Liberación desde Puebla. Medellín, Bogotá, v. 5, n. 19, p. 358-387, 1979.

MALLIMACI, F. (Ed). Religión y política: perspectivas desde América Latina y Europa. Buenos Aires: Biblos, 2008.

MARTIN, P. El Movimiento de Sacerdotes para el Tercer Mundo: un debate argentino. Buenos Aires: UNGS, 1992.

MENDIETA, E.; VAN ANTWERPEN, J. El poder de la religión en la esfera pública. Madrid: Trotta, 2011.

MONOD, J-C. La querelle de la sécularisation. Théologie politique et philosophies de l' histoire de Hegel a Blumenberg Paris: J. Vrin, 2012.

PAGANELLI, P. Del claustro monacal a la bayoneta empuñada: Iglesia Católica y Violencia Política en Colombia (1950-1975). Conflicto Social, Buenos Aires, v. 9, n. 5, p. 105-129, 2016.

RAMÍREZ, J. El movimiento sacerdotal ONIS: la Iglesia en el Perú ante las demandas de justicia social, 1968-1975. Tesis (Licenciado en Historia) - Universidad Nacional de San Marcos, Lima, 2006. 
RAMÍREZ-TRILLOS, O.; PLATA-QUEZADA, W. Theologica Xaveriana y la construcción de una teología colombiana. El concepto "evangelización" (1974-1991). Theologica Xaveriana, Bogotá, v. 70, 2020.

RAMMINGER, M. Éramos Iglesia...en medio del pueblo: el legado de los Cristianos por el Socialismo en Chile, 1971-1973. Santiago: LOM, 2019.

RESTREPO, J. La Revolución de las Sotanas: golconda 25 años después. Bogotá: Planeta, 1995.

RICHARD, P. Cristianismo, lucha ideológica y racionalidad socialista. Salamanca: Sígueme, 1975.

RODRIGUES, C.; ZANOTTO, G.; COPPE CALDEIRA, R. (Ed.). Manifestações do pensamento católico na América do Sul. Rio Grande do Sul: Fonte-FAPERGS, 2015.

SCHICKENDANTZ, C. Autoridad teológica de los acontecimientos históricos. Perplejidades sobre un lugar teológico. Teología, Buenos Aires, v. 50 n 115, p. 157-183, 2014.

STUVEN, A. M. La religión en la esfera pública chilena: ¿laicidad o secularización?. Santiago: Ediciones UDP, 2014.

TAYLOR, C. Una Edad Secularizada. Barcelona, Gedisa, 2009.

Artículo sometido en 25.01.21 y aprobado en 12.04.21.

Marcos Jesús Fernández Labbé es Doctor en Historia y actualmente se desempeña como Director del Departamento de Historia de la Universidad Alberto Hurtado. Sus temas de investigación se relacionan con la Historia del Catolicismo Contemporáneo en América Latina desde la perspectiva de la Historia Intelectual. Orcid.org/0000-0003-0017-7378. E-mail: mfernand@uahurtado.cl

Dirección: Alameda 1869, of. 325

Santiago de Chile 